I N S T I T U T O

$\mathrm{DE}$

M E D I C I N A

T R O P I C A L

DE

SÃO PAULO

JOURNAL OF THE SÃO PAULO INSTITUTE OF TROPICAL MEDICINE

${ }^{1}$ Hospital Unimed-Rio, Unidade de Terapia Intensiva, Rio de Janeiro, Rio de Janeiro, Brazil

${ }^{2}$ Instituto Nacional de Cardiologia, Rio de Janeiro, Rio de Janeiro, Brazil

${ }^{3}$ Fiocruz, Instituto Nacional de Infectologia Evandro Chagas, Rio de Janeiro, Rio de Janeiro, Brazil

${ }^{4}$ Universidade Unigranrio, Rio de Janeiro, Rio de Janeiro, Brazil

${ }^{5}$ Instituto Unimed-Rio, Rio de Janeiro, Rio de Janeiro, Brazil

Correspondence to: Rafael Lessa da

Costa

Hospital Unimed-Rio, Unidade de Terapia Intensiva, Av. Ayrton Senna, 2550, CEP 22775-003, Rio de Janeiro, RJ, Brazil

Tel: +55 21995116963

E-mail: lessa.med@gmail.com

Received: 26 August 2021

Accepted: 15 December 2021

\section{Secondary infections in a cohort of patients with COVID-19 admitted to an intensive care unit: impact of gram-negative bacterial resistance}

\author{
Rafael Lessa da Costa ${ }^{(1)}$, Cristiane da Cruz Lamas ${ }^{(2,3,4}$, Luiz Fernando \\ Nogueira Simvoulidis ${ }^{1}$, Claudia Adelino Espanha ${ }^{1}$, Lorena Pinto \\ Monteiro Moreira ${ }^{1}$, Renan Alexandre Baptista Bonancim ${ }^{1}$, João Victor \\ Lehmkuhl Azeredo Weber ${ }^{(15}$, Max Rogerio Freitas Ramos ${ }^{(15}$, Eduardo Costa \\ de Freitas Silva ${ }^{-5}$, Liszt Palmeira de Oliveira ${ }^{-5}$
}

\section{ABSTRACT}

Some studies have shown that secondary infections during the COVID-19 pandemic may have contributed to the high mortality. Our objective was to identify the frequency, types and etiology of bacterial infections in patients with COVID-19 admitted to an intensive care unit (ICU) and to evaluate the results of ICU stay, duration of mechanical ventilation (MV) and inhospital mortality. It was a single-center study with a retrospective cohort of patients admitted consecutively to the ICU for more than $48 \mathrm{~h}$ between March and May 2020. Comparisons of groups with and without ICU- acquired infection were performed. A total of 191 patients with laboratory-confirmed COVID-19 were included and 57 patients had 97 secondary infectious events. The most frequent agents were Acinetobacter baumannii (28.9\%), Pseudomonas aeruginosa (22.7\%) and Klebsiella pneumoniae (14.4\%); multi-drug resistance was present in $96 \%$ of A. baumannii and in $57 \%$ of $K$. pneumoniae. The most prevalent infection was ventilator-associated pneumonia in $57.9 \%$ of patients with bacterial infections, or $17.3 \%$ of all COVID-19 patients admitted to the ICU, followed by tracheobronchitis (26.3\%). Patients with secondary infections had a longer ICU stay (40.0 vs. 17 days; $\mathrm{p}<0.001$ ), as well as a longer duration of MV (24.0 vs 9.0 days; $p=0.003)$. There were $68(35.6 \%)$ deaths overall, of which 27 (39.7\%) patients had bacterial infections. Among the 123 survivors, $30(24.4 \%)$ had a secondary infections (OR 2.041; 95\% CI 1.080 - 3.859). A high incidence of secondary infections, mainly caused by gram-negative bacteria has been observed. Secondary infections were associated with longer ICU stay, MV use and higher mortality.

KEYWORDS: COVID-19. Secondary infections. Healthcare associated infection. Intensive care unit. Gram negatives. Multidrug-resistance. Ventilator-associated pneumonia.

\section{INTRODUCTION}

The disease caused by the new coronavirus (COVID-19) has already affected more than 116 million people in more than 180 countries and has caused at least 2.5 million deaths. Brazil is the third country with the most cases in the world and the second with the highest number of fatalities ${ }^{1}$.

Some studies have shown that secondary infections during the COVID-19 pandemic may have contributed to the high mortality ${ }^{2}$. A review of samples from influenza victims from 1918-1919 showed that most deaths probably resulted directly from secondary bacterial pneumonia caused by common upper respiratory 
tract bacteria ${ }^{3}$. During the influenza A pandemic in 2009, bacterial complications were present in approximately one out of four severe or fatal cases, with greater morbidity in adults and patients admitted to the Intensive Care Unit $(\mathrm{ICU})^{4}$. Although the clinical profile and mortality rate of patients with severe COVID-19 have been previously published $^{5-7}$, infections acquired in the hospital, related to healthcare, are still little known and this knowledge may contribute to better results in the clinical management of patients and to improve the outcomes.

The primary objective of this study is to identify the incidence, etiology and types of ICU-acquired secondary infections in patients with COVID-19 in a hospital in Rio de Janeiro, Brazil. The secondary objective is to assess the length of stay in the ICU, duration of mechanical ventilation and in-hospital mortality in this population.

\section{Ethical approval and consent to participate}

This study was approved by the Comite de Etica em Pesquisa da Universidade do Estado do Rio de Janeiro, approved opinion $\mathrm{N}^{\mathrm{o}}$ 4.036.509. Informed consent was waived by the Comite de Etica em Pesquisa da Universidade do Estado do Rio de Janeiro due to the retrospective nature of the study.

\section{MATERIALS AND METHODS}

\section{Study design}

Our study was designed as a retrospective cohort of patients admitted consecutively to the ICU. A single-center study was conducted in a private hospital in Southeastern Brazil, by consulting the electronic medical records of adult patients consecutively admitted to the ICU, diagnosed with COVID-19 confirmed by reverse transcription-polymerase chain reaction from nasopharyngeal swabs ${ }^{8}$. The study period was 17 March to 27 May 2020.

\section{Population}

Patients were classified into two groups: the first group was composed of those patients with ICUacquired secondary infections and the other group was composed of patients without secondary infections, so as to assess the impact of secondary infections on the patients' outcomes. All patients had been in the ICU for more than $48 \mathrm{~h}$ and were 18 years old or older. The microbiological investigation and treatment decisions were not standardized and were made by the attending physicians. All patients had received a third generation cephalosporin associated with azythromycin, as per protocol for severe COVID-19 presentation at the time ${ }^{9}$.

\section{Microbiology}

Bacterial cultures were obtained from blood, urine or respiratory samples using the BacT/Alert (BioMérieux, France) system, and the pathogen's identification was carried out by Vitek 2 (BioMérieux, France). Antimicrobial susceptibility testing was performed by the standard disk-diffusion method in accordance with the Clinical \& Laboratory Standards Institute ${ }^{10}$. Fungal or viral infections were not considered in this study.

\section{Definitions}

Diagnoses of hospital-acquired pneumonia (HAP), ventilator-associated pneumonia (VAP), central line-associated bloodstream infections (CLABSI) and catheter-associated urinary tract infection (CAUTI) followed the criteria of the Centers for Disease Control and Prevention National Healthcare Safety Network ${ }^{11}$. The modified Duke's criteria were used to diagnose infective endocarditis ${ }^{12}$. Multidrug resistance (MDR) was defined according to the European Centre for Disease Prevention and Control and the Centers for Disease Control and Prevention ${ }^{13}$. The definition used for secondary infectious events was the occurrence of clinical or laboratory signs of infection, such as fever or hypothermia, increased C-reactive protein (CRP) levels, increased levels of procalcitonin, altered white blood cells count or abnormalities in the imaging studies, more than 2 days after the ICU admission; secondary infections were considered as distinct events when different microorganisms were isolated. In all cases of suspected secondary infections, biological samples for culture were collected in accordance with the guidance of the assistant medical team and the suspected involved site.

\section{Population characteristics}

For the description of the population, the following data were obtained: age, sex, body mass index - BMI $\left(\mathrm{kg} / \mathrm{m}^{2}\right)$, Simplified Acute Physiology Score 3 (SAPS 3), presence or absence of systemic arterial hypertension (SAH), diabetes mellitus (DM), asthma, chronic obstructive pulmonary disease (COPD), coronary artery disease, left ventricular dysfunction, solid organ cancer, date of onset of symptoms, length of stay in the ICU, length of hospital stay and clinical complications (acute respiratory distress syndrome - ARDS, according to Berlin criteria ${ }^{14}$, need for invasive ventilatory support, use of vasopressor drugs, presence of venous thromboembolism and death). 
Data collection and interpretation of culture results from biological samples were carried out by medical researchers LPMM and RABB. The divergences were resolved by consensus and, whenever necessary, by a third reviewer (CAE).

\section{Statistical analysis}

Continuous variables with normal distribution were expressed as means and standard deviations and continuous variables without normal distribution were expressed as medians and interquartile ranges; categorical variables were expressed as absolute values and relative frequency. Normality tests were performed using the Shapiro-Wilk model. Comparisons between continuous variables were performed using the unpaired Student's t test or the MannWhitney U test. For comparisons of categorical variables, the chi-square test was used. Logistic regression analysis was performed to determine the predictors of secondary infection. Variables that were associated with secondary infections at a significance level of $p<0.20$ were included in the multivariate regression model. The stepwise forward method was used. The magnitude of the effect of each variable was estimated by calculating the odds ratio $(\mathrm{OR})$ and their respective $95 \%$ confidence intervals (CI). The tests were two-tailed and the statistical significance was expressed as $\mathrm{p}<0.05$. The data were analyzed using SPSS version 20.0 (IBM Corp., Armonk, NY, USA).

\section{RESULTS}

\section{Occurrence of infections}

A total of 191 adult patients were consecutively admitted to the ICU with a laboratory-confirmed diagnosis of COVID-19; the majority was male $(60.7 \%)$ and the median age was 70.5 years $(58.5-80.1)$. Clinical features of all patients and of the groups with and without ICU-acquired secondary infections are shown in Table 1. The median time between hospital admission and infection was 17 days, and 57 (29.8\%) patients had 97 secondary infectious events (Table 2). The most prevalent agents and sites of secondary infections are shown in Table 3. The most frequent agents were Acinetobacter baumanii (28/97; 28.9\%), Pseudomonas aeruginosa $(22 / 97 ; 22.7 \%)$ and Klebsiella pneumoniae (14/97; 14.4\%). Multi-drug resistance was present in 27/28 (96\%) A. baumannii and in $8 / 14(57 \%)$ K. pneumoniae. At least 48 (49.5\%) events were due to bacteria presenting with some antimicrobial resistance profile. The most prevalent bacterial infection was VAP in 33/57 (57.9\%) patients, or 33/191(17.3\%) of all COVID-19 patients admitted to the ICU, followed by tracheobronchitis in 15 (26.3\%) patients. Table 4 presents a comparison of patients who died with respect to those who survived, stratified by type of infection. The secondary infections found were VAP $(45 / 97 ; 46 \%)$, tracheobronchitis $(21 / 97 ; 22 \%)$, CLABSI $(17 / 97 ; 18 \%)$, CAUTI $(6 / 97 ; 6.2 \%)$, HAP $(5 / 97 ; 5.2 \%)$, osteomyelitis $(2 / 97,2.0 \%)$ and endocarditis $(1 / 97 ; 1.0 \%)$. The median time from hospital admission to the occurrence of infection was 17 days (IQR 10 - 35.5 days).

\section{Outcomes}

Patients with secondary infections had a longer ICU stay, in days, compared to patients without infection [40.0 (30.0 - 46.0) x $17.0(11.0$ - 26.0); p < 0.001], as well as a longer time on mechanical ventilation

Table 1 - Clinical and laboratory features of 191 adult patients with COVID-19 admitted to the ICU and stratified according to presence of ICU-acquired secondary infections.

\begin{tabular}{|c|c|c|c|c|}
\hline & $\begin{array}{l}\text { All patients } \\
(n=191)\end{array}$ & $\begin{array}{c}\text { Patients with } \\
\text { secondary infections } \\
(n=57)\end{array}$ & $\begin{array}{l}\text { Patients without } \\
\text { secondary infections } \\
(n=134)\end{array}$ & $p$-value \\
\hline \multicolumn{5}{|l|}{ Characteristics } \\
\hline Age (years) & $70.5[58.5-80.1]$ & $73.3[63.6-77.5]$ & $56.2[45.5-78.1]$ & 0.9270 \\
\hline Male & $116(60.7 \%)$ & $38(66.7 \%)$ & 78 (58.2\%) & 0.2730 \\
\hline $\mathrm{BMI}\left(\mathrm{kg} / \mathrm{m}^{2}\right)$ & $32.0[25.0-33.0]$ & $31.0[26.0-35.0]$ & $30.0[27.0-35.0]$ & 0.1240 \\
\hline $\begin{array}{l}\text { eGRF (on admission) } \\
\left(\mathrm{mL} / \mathrm{min} / 1.73 \mathrm{~m}^{2}\right)\end{array}$ & $67.9 \pm 30.0$ & $72.7 \pm 31.8$ & $80.0 \pm 33.3$ & 0.0540 \\
\hline $\begin{array}{l}\Delta \text { symptoms-hospitalization (days) due } \\
\text { to COVID-19 }\end{array}$ & $7.0[4.0-9.0]$ & $6.0[4.0-8.0]$ & $7.0[5.0-8.0]$ & 0.0310 \\
\hline SAPS 3 & $45.0[29.0-71.0]$ & $75.0[53.0-82.0]$ & $48.0[40.0-71.0]$ & 0.0001 \\
\hline CRP levels (mg/L) & $10.0[6.0-21.0]$ & $18.0[7.0-26.0]$ & $14.0[7.0-25.0]$ & 0.0070 \\
\hline
\end{tabular}


Table 1 - Clinical and laboratory features of 191 adult patients with COVID-19 admitted to the ICU and stratified according to presence of ICU-acquired secondary infections. (cont.)

\begin{tabular}{|c|c|c|c|c|}
\hline & $\begin{array}{l}\text { All patients } \\
(n=191)\end{array}$ & $\begin{array}{c}\text { Patients with } \\
\text { secondary infections } \\
(n=57)\end{array}$ & $\begin{array}{l}\text { Patients without } \\
\text { secondary infections } \\
(n=134)\end{array}$ & $p$-value \\
\hline \multicolumn{5}{|l|}{ Comorbidities } \\
\hline Systemic arterial hypertension & $122(63.9 \%)$ & $39(68.4 \%)$ & $83(61.9 \%)$ & 0.3940 \\
\hline Diabetes & $72(37.7 \%)$ & $16(28.1 \%)$ & $56(41.8 \%)$ & 0.0730 \\
\hline Asthma & $8(4.2 \%)$ & $1(1.8 \%)$ & $7(5.2 \%)$ & 0.2730 \\
\hline COPD & $14(7.3 \%)$ & $2(3.5 \%)$ & $12(9.0 \%)$ & 0.1860 \\
\hline Coronary disease & $22(11.5 \%)$ & $7(12.3 \%)$ & $15(11.2 \%)$ & 0.8300 \\
\hline Ventricular dysfunction & $12(6.2 \%)$ & $4(7.1 \%)$ & $8(5.9 \%)$ & 0.3970 \\
\hline Cancer & $12(6.2 \%)$ & $3(5.3 \%)$ & $9(6.7 \%)$ & 0.7050 \\
\hline Use of corticosteroids in the ICU & $34(24.3 \%)$ & $16(34.8 \%)$ & $18(19.1 \%)$ & 0.0430 \\
\hline \multicolumn{5}{|l|}{ Complications } \\
\hline ARDS mild & $21(11.0 \%)$ & $8(14.0 \%)$ & $13(9.7 \%)$ & 0.3810 \\
\hline ARDS moderate and severe & $98(51.3 \%)$ & $47(82.4 \%)$ & $51(38.0 \%)$ & 0.0001 \\
\hline Hemodialysis & $55(28.8 \%)$ & $33(57.9 \%)$ & $22(16.4 \%)$ & 0.0001 \\
\hline Mechanical ventilation & $115(60.2 \%)$ & $56(98.2 \%)$ & $59(44.0 \%)$ & 0.0001 \\
\hline Use of vasopressors & $109(57.4 \%)$ & $56(98.2 \%)$ & $53(39.8 \%)$ & 0.0001 \\
\hline VTE & $30(15.7 \%)$ & $13(22.8 \%)$ & $17(12.7 \%)$ & 0.0790 \\
\hline \multicolumn{5}{|l|}{ Hospitalization data } \\
\hline Length of ICU stay (days) & $9.5[3.2-26.0]$ & $40.0[30.0-46.0]$ & $17.0[11.0-26.0]$ & 0.0001 \\
\hline $\begin{array}{l}\text { Duration of mechanical ventilation } \\
\text { (days) }\end{array}$ & $13.0[8.0-24.2]$ & $24.0[11.0-29.0]$ & $9.0[5.0-15.0]$ & 0.0030 \\
\hline Length of hospital stay (days) & $14.5[9.0-32.0]$ & $48.0[33.0-54.0]$ & $24.0[18.0-36.0]$ & 0.0001 \\
\hline Death & $68(35.6 \%)$ & 27 (47.4\%) & $41(30.6 \%)$ & 0.0270 \\
\hline
\end{tabular}

ARDS = acute respiratory distress syndrome; BMI = body mass index; COPD = chronic obstructive pulmonary disease; CRP = C-reactive protein; eGRF = estimated glomerular rate filtration; SAPS 3 = Simplified Acute Physiology Score 3; VTE = venous thromboembolism.

[24.0 $(11.0-29.0) \times 9.0(5.0-15.0) ; \mathrm{p}=0.003]$. There were 68/191 (35.6\%) deaths overall and of these, 27 (39.7\%) patients had secondary infections, whereas in the group of 123 survivors, only $30(24.4 \%)$ had secondary infections (OR 2.041; 95\% CI 1.080 - 3.859; $\mathrm{p}=0.0270$ ). There was a greater distribution of VAP cases in the group of patients who died compared to those who survived (30.9\% x 9.8\%; OR 4.133; 95\% CI $1.881-9.079 ; \mathrm{p}<0.001)$, as shown in Table 4.

The bivariate analysis showed an association of secondary infections with the following variables: SAPS 3 , CRP level, use of corticosteroids in the ICU, moderate ARDS, hemodialysis, mechanical ventilation, use of vasopressors and duration of mechanical ventilation, as shown in Table 5. However, the multivariate analysis showed an association only with the SAPS 3 score (OR $1.093 ; 95 \%$ CI $1.016-1.175 ; \mathrm{p}=0.017$ ).

\section{DISCUSSION}

In our retrospective observational cohort of 191 patients, we observed a high prevalence of infections acquired in the ICU and a predominance of gram-negative bacteria, especially multiresistant $A$. baumannii and K. pneumoniae. These data may reflect the challenges experienced in an ICU dedicated to the care of patients with COVID-19, that was forced to adapt dynamically according to the local pandemic scenario in order to keep the patients alive in the face of a new highly contagious and severe disease without specific treatment, in addition to the flows and protocols already established for the control of nosocomial infections. Few studies on secondary infections in the ICU setting have been published despite the fact it is an important topic for the management of critically ill patients with COVID-19. A meta-analysis 
Table 2 - Etiological agents identified in ICU-acquired superinfections of 57 adult patients admitted due to COVID-19.

\begin{tabular}{|c|c|}
\hline Etiological agent & $\mathrm{n}(\%)$ \\
\hline Acinetobacter baumannii & $28(28.9 \%)$ \\
\hline Multi-drug resistant ${ }^{a} A$. baumannii & $27(27.8 \%)$ \\
\hline Pseudomonas aeruginosa & $22(22.8 \%)$ \\
\hline Carbapenem-resistant $P$. aeruginosa & $4(4.1 \%)$ \\
\hline Multi-drug resistant ${ }^{\mathrm{b}} P$. aeruginosa & $1(1.0 \%)$ \\
\hline Klebsiella pneumoniae & $14(14.6 \%)$ \\
\hline Multi-drug resistant ${ }^{c} K$. pneumoniae & $8(8.2 \%)$ \\
\hline $\begin{array}{l}\text { K. pneumoniae with expanded spectrum to } \\
\text { beta-lactamases }\end{array}$ & $3(3.1 \%)$ \\
\hline Carbapenem-resistant K. pneumoniae & $1(1.0 \%)$ \\
\hline Staphylococcus aureus & $8(8.2 \%)$ \\
\hline Methicillin resistant S. aureus & $4(4.1 \%)$ \\
\hline Enterococcus faecalis & $7(7.2 \%)$ \\
\hline Stenotrophomonas maltophilia & $6(6.2 \%)$ \\
\hline Burkholderia cepacia & $2(2.0 \%)$ \\
\hline Candida sp. & $3(3.1 \%)$ \\
\hline Enterobacteria $^{\mathrm{d}}$ & $4(4.0 \%)$ \\
\hline Others $^{b}$ & $3(3.0 \%)$ \\
\hline Total & $97(100 \%)$ \\
\hline
\end{tabular}

asensitive to colistin and tigecycline only; 'btaphylococcus haemolyticus, Chryseobacterium indologenes; 'sensitive to ceftazidime/avibactam only; ${ }^{\text {d }}$ Enterobacter aerogenes, Escherichia coli, Enterobacter cloacae.

of 3,448 patients assessed the prevalence of coinfections and secondary infections in patients with COVID-19 and found presence of coinfections in $3.5 \%$ of patients and of secondary infections in $15.5 \%$, with a greater proportion among the most severely ill individuals. Interestingly, despite the low incidence of bacterial coinfections, more than $70 \%$ of patients received antimicrobials ${ }^{15}$. Moreover, as already reported, the self-administration of antibiotics was 33\% among COVID-19 patients in Peru, and although there is some regulation in Brazil, this may have also been a contributing factor for the selection of resistant bacteria in our patients' cohort $^{16}$. Therefore, not only infection control practices play a role in the acquisition of infection in ICU's during the COVID-19pandemic, but antibiotic overuse may also select multiresistant bacteria ${ }^{15}$. Ripa et al. ${ }^{17}$ showed that a secondary infection was observed in $9.3 \%$ of 731 patients hospitalized due to COVID-19 in Italy. Incidence of healthcare related bacterial pneumonia in patients admitted due to COVID-19 was 0.4 per 1,000 days of follow-up outside the ICU vs 15.2 in ICU, that is, incidence was 37 -fold higher in ICU. Gram-negative bacteria predominated in their study, of which Acinetobacter accounted for the greater portion (nearly a third of the cases). Risk factors for secondary infections in the multivariate analysis were early need for ICU, respiratory failure and severe baseline lymphopenia. A report on patients with COVID-19 in 19 ICUs in China showed that carbapenem-resistant Acinetobacter (CRAB) was identified in 19/30 isolates related to secondary infections, of which most were VAP. A CRAB outbreak during the COVID-19 pandemic has been reported in the $\mathrm{USA}^{18}$; the report states that the response to COVID-19related care infections required changes such as frequent patient's bathing with chlorhexidine gluconate that led to a $43 \%$ reduction in screening tests to detect CRAB. To make matters worse, there were critical shortages of nursing and environmental services resulting from staff members' illness and quarantine. In Lille, France, an OXA-23-producing Acinetobacter baumannii outbreak occurred during the COVID-19 epidemic in their ICUs; CRAB was found in respiratory and blood samples taken from 21 patients, all of them on mechanical ventilation ${ }^{19}$. Environmental sampling was performed on equipment such as ECG devices, ultrasound scanner, hemodialysis machine, but CRAB was not recovered from these equipments. A small Iranian study on 19 patients admitted to an ICU, all on mechanical ventilation, showed that all patients acquired infections, and 17 of them had multiresistant Acinetobacter as the causative agent of VAP; mortality was $95 \%{ }^{20}$. In Spain, from a total of 712 patients hospitalized with COVID-19, 11\% developed secondary infections, and Acinetobacter sensitive to colistin was the main pathogen in pneumonia and bloodstream infections that were considered an outbreak at the time; the authors reported that this pathogen was very uncommon in their hospital. The multivariate analysis showed that bacteremia and secondary infections due to Acinetobacter were associated with mortality ${ }^{21}$. Another Spanish cohort of 989 consecutively hospitalized patients found a 3.8\% overall incidence of secondary infections in patients with COVID-19, but the proportion of cases was higher among individuals admitted to the ICU and they accounted for more than half of the secondary infections. Gram-negative bacteria were also the most prevalent in this study and $28 \%$ of those who developed infections in the ICU had at least one bacterium with a multidrug resistant profile identified. Longer hospital stays and higher mortality were observed in those who evolved with healthcare-related infections ${ }^{22}$.

A small Chinese cohort study with 36 ICU patients found a prevalence of secondary bacterial infections of $13.9 \%$. The most common agents found in cultures were Burkholderia cepacia, Stenotrophomonas maltophilia and Pseudomonas aeruginosa, all isolated from tracheal aspirates or bronchoalveolar lavages, showing that exposure to mechanical ventilation preceded the occurrence of these 
Table 3 - Secondary infections in 191 patients with COVID-19 in an ICU in Brazil, stratified by etiologic agents and sites of infection.

\begin{tabular}{|c|c|}
\hline Acinetobacter baumannii & $n=28$ \\
\hline \multicolumn{2}{|l|}{ Isolated biological material } \\
\hline Tracheal aspirate & $20(71.2 \%)$ \\
\hline Blood and tracheal aspirate & $3(10.8)$ \\
\hline Blood & $2(7.2 \%)$ \\
\hline BAL & $1(3.6 \%)$ \\
\hline Urine & $1(3.6 \%)$ \\
\hline Bone fragment & $1(3.6 \%)$ \\
\hline \multicolumn{2}{|l|}{ Type of infection } \\
\hline VAP & $14(50.0 \%)$ \\
\hline Tracheobronchitis & $9(32.1 \%)$ \\
\hline CLABSI & $2(7.1 \%)$ \\
\hline Nosocomial pneumonia & $1(3.6 \%)$ \\
\hline Osteomyelitis & $1(3.6 \%)$ \\
\hline CAUTI & $1(3.6 \%)$ \\
\hline Pseudomonas aeruginosa & $\mathrm{n}=\mathbf{2 2}$ \\
\hline \multicolumn{2}{|l|}{ Isolated biological material } \\
\hline Tracheal aspirate & $17(77.4 \%)$ \\
\hline Blood and tracheal aspirate & $2(9.1 \%)$ \\
\hline Blood & $1(4.5 \%)$ \\
\hline BAL & $1(4.5 \%)$ \\
\hline Bone fragment & $1(4.5 \%)$ \\
\hline \multicolumn{2}{|l|}{ Type of infection } \\
\hline VAP & $11(50.0 \%)$ \\
\hline Tracheobronchitis & $8(36.5 \%)$ \\
\hline CLABSI & $1(4.5 \%)$ \\
\hline Nosocomial pneumonia & $1(4.5 \%)$ \\
\hline Osteomyelitis & $1(4.5 \%)$ \\
\hline Klebsiella pneumoniae & $n=14$ \\
\hline \multicolumn{2}{|l|}{ Isolated biological material } \\
\hline Tracheal aspirate & $6(42.8 \%)$ \\
\hline Blood & $8(57.2 \%)$ \\
\hline \multicolumn{2}{|l|}{ Type of infection } \\
\hline VAP & $7(50.0 \%)$ \\
\hline CLABSI & $4(28.6 \%)$ \\
\hline Nosocomial pneumonia & $3(21.4 \%)$ \\
\hline
\end{tabular}

\begin{tabular}{lc}
\hline Stenotrophomonas maltophilia & $\mathbf{n = 6}$ \\
\hline $\begin{array}{l}\text { Isolated biological material } \\
\quad \text { Tracheal aspirate }\end{array}$ & $5(83.3 \%)$ \\
$\quad$ Blood and tracheal aspirate & $1(16.7 \%)$ \\
Type of infection & \\
VAP & $5(83.3 \%)$ \\
$\quad$ Tracheobronchitis & $1(16.7 \%)$ \\
\hline Staphylococcus aureus & $\mathbf{n = 8}$
\end{tabular}

Isolated biological material

Blood $2(25.0 \%)$

Tracheal aspirate $4(50.0 \%)$

Blood and tracheal aspirate $\quad 2(25.0 \%)$

Type of infection

VAP $5(62.5 \%)$

Tracheobronchitis $1(12.5 \%)$

CLABSI $1(12.5 \%)$

\begin{tabular}{lc} 
Endocarditis & $1(12.5 \%)$ \\
\hline Enterococcus faecalis & $\mathbf{n = 6}$ \\
\hline
\end{tabular}

Isolated biological material

Blood $4(66.6 \%)$

Tracheal aspirate $\quad 1(16.7 \%)$

Urine $1(16.7 \%)$

Type of infection

CLABSI $3(50.0 \%)$

CAUTI 2 (33.3\%)

\begin{tabular}{cc} 
VAP & $1(16.7 \%)$ \\
\hline Others & $\mathbf{n = 1 3}$
\end{tabular}

$\mathrm{BAL}=$ bronchoalveolar lavage; CAUTI = catheter-associated urinary tract infection; CLABSI = central line-associated bloodstream infections; VAP = ventilator-associated pneumonia.

Table 4 - Comparison of patients who died and survived in 191 adult patients with COVID-19 admitted to ICU, stratified by type of superinfection.

\begin{tabular}{lcccccc}
\hline Total number of patients & & $\begin{array}{c}\text { Deaths } \\
(\mathrm{n}=68)\end{array}$ & $\begin{array}{c}\text { Survivors } \\
(\mathrm{n}=123)\end{array}$ & OR & $\mathrm{Cl} 95 \%$ & $\mathrm{p}$-value \\
\hline $\begin{array}{l}\text { Patients with } \\
\text { superinfection }\end{array}$ & 57 & $27(39.7 \%)$ & $30(24.4 \%)$ & 2.041 & $1.080-3.859$ & $\mathbf{0 . 0 2 7 0}$ \\
VAP & 33 & $21(30.9 \%)$ & $12(9.8 \%)$ & 4.133 & $1.881-9.079$ & $\mathbf{0 . 0 0 0 1}$ \\
CLABSI & 14 & $7(10.3 \%)$ & $7(5.7 \%)$ & 1.902 & $0.638-5.670$ & 0.2430 \\
CAUTI & 6 & $1(1.5 \%)$ & $5(4.1 \%)$ & 0.215 & $0.026-1.753$ & 0.1160 \\
Tracheobronchitis & 15 & $4(5.9 \%)$ & $11(8.9 \%)$ & 0.636 & $0.195-2.081$ & 0.4510 \\
\hline
\end{tabular}

CAUTI = catheter-associated urinary tract infection; CLABSI = central line-associated bloodstream infections; VAP = ventilatorassociated pneumonia.

infections. In this cohort, multidrug resistant bacteria were not found ${ }^{23}$. Another Chinese study with 38 severe and critical
COVID-19 patients showed a $57.9 \%$ prevalence of secondary infections, most of which (21/22) were respiratory, with gram 
Table 5 - Bivariate analysis of factors related to the outcome of ICU-acquired superinfections in 191 adult patients admitted to ICU due to COVID-19.

\begin{tabular}{lccc}
\hline \multirow{2}{*}{ Variables } & & Bivariate & \\
\cline { 2 - 4 } Age (years) & OR & Cl 95\% & 0.905 \\
Male & 1.001 & $0.981-1.022$ & 0.275 \\
BMI $\left(\mathrm{Kg} / \mathrm{m}^{2}\right)$ & 0.696 & $0.364-1.333$ & 0.104 \\
Egrf & 1.044 & $0.991-1.099$ & 0.056 \\
Hypertension & 0.990 & $0.979-1.000$ & 0.394 \\
Diabetes & 0.751 & $0.389-1.451$ & 0.075 \\
SAPS 3 & 1.840 & $0.939-3.603$ & $\mathbf{0 . 0 0 1}$ \\
CRP & 1.035 & $1.019-1.051$ & $\mathbf{0 . 0 0 5}$ \\
Use of corticosteroids in the ICU & 1.039 & $1.011-1.068$ & $\mathbf{0 . 0 4 5}$ \\
ARDS mild & 2.252 & $1.017-4.987$ & 0.384 \\
ARDS moderate and severe & 1.520 & $0.593-3.895$ & $\mathbf{0 . 0 0 1}$ \\
Hemodialysis & 7.025 & $3.335-14.801$ & $\mathbf{0 . 0 0 1}$ \\
Mechanical ventilation & 7.000 & $3.488-14.050$ & $\mathbf{0 . 0 0 1}$ \\
Vasopressor drug & 71.186 & $9.571-529.47$ & $\mathbf{0 . 0 0 1}$ \\
VTE & 84.528 & $11.35-629.36$ & 0.082 \\
Time on mechanical ventilation (days) & 2.033 & $0.913-4.530$ & $\mathbf{0 . 0 1 1}$ \\
\hline ARDS acute respiatory distress syndrome; & 1.125 & $1.028-1.231$ & \\
\hline
\end{tabular}

ARDS = acute respiratory distress syndrome; BMI = body mass index; CRP = C-reactive protein; eGRF = estimated glomerular rate filtration; SAPS 3 = Simplified Acute Physiology Score 3; VTE = venous thromboembolism.

negative bacteria responsible for half of the cases. No mention of multidrug resistant bacteria was made ${ }^{24}$.

In France, a prospective cohort of 54 ICU patients reported that had $49(90.7 \%)$ of the patients were on invasive mechanical ventilation. Cultures of bronchoalveolar lavage identified secondary bacterial infections in 20 (37\%) inpatients, and of this total, 15 (75\%) were VAP. In our study, the incidence of secondary infections was $29.8 \%$ of which $33 / 57$ (58\%) were VAP. However, their profile of etiologic agents showed a higher prevalence for Stenotrophomonas maltophilia, Staphylococcus aureus and Pseudomonas aeruginosa with 13\%, 20\% and 33\%, respectively, while in our study we had Acinetobacter, P. aeruginosa and K. pneumoniae, in $28.9 \%, 22.7 \%$ and $14.4 \%$, respectively. Patients who developed VAP presented a higher proportion of ARDS and acute kidney injury and they remained on mechanical ventilation and in the ICU for longer periods ${ }^{25}$. We found similar risk factors in our study: the group of patients with secondary infections presented here experienced moderate to severe ARDS, the need for hemodialysis, mechanical ventilation and vasopressor drugs. They also remained for longer periods of time on mechanical ventilation in the ICU and there was a higher proportion of deaths among these patients. Furthermore, a study in Qatar evaluated the impact of MDR gram- negative infections in patients with severe COVID-19 admitted to an ICU. They found a total of 78 cases of MDR-gram negative infections out of 1,231 adults (incidence 4.5 per 1,000 ICU days); 98 MDR gram-negative isolates were retrieved within a median of nine days of admission to the ICU. More than one MDR gram-negative was isolated from $17(21.8 \%)$ patients. The most frequent sample sites were the respiratory tract $(74,75.5 \%)$ and blood $(18,18.4 \%)$. The most frequently isolated MDR gram-negative bacteria were Stenotrophomonas maltophilia (24, 24.5\%), Klebsiella pneumoniae (23, 23.5\%) and Enterobacter cloacae (18, $18.4 \%)$; the authors hypothesized one or more outbreaks to account for these findings. Mechanical ventilation days, not receiving corticosteroids or tocilizumab were independently associated with the isolation of MDR gram -negative bacteria. Surprisingly, there was no association between MDR gram-negative infections and the 28-day all-cause mortality ${ }^{26}$.

A retrospective cohort of 78 patients in Italy investigated the occurrence of CLABSI in ICU patients with COVID-19. They found a high incidence of events, with a higher prevalence of coagulase-negative staphylococci, followed by Enterococcus faecalis and Staphylococcus aureus. The multivariate analysis showed only the use of anti-inflammatory agents such as tocilizumab or methylprednisolone as independent factors associated with the occurrence of $\mathrm{CLABSI}^{27}$. In our study, of the 57 patients with secondary infections, $14(24.6 \%)$ were diagnosed with CLABSI, with a predominance of gram- 
negative bacteria. Recently, a study from the CDC looked at the impact of COVID-19 on the incidence of healthcareassociated infections (HAIs) in U.S. hospitals ${ }^{28}$. Substantial increases in HAI and antibiotic-resistance were observed in 2020 in comparison with 2019. Ventilator-associated events increased in all the 2020 quarters compared to 2019; these increments varied from 11.3 to $44.8 \%$. The COVID-19 pandemic created a somber scenario for HAI and antimicrobial resistance. Many hospitals faced difficult circumstances that reduced the maintenance of standard infection prevention and control measures.

In our population, the most prevalent gram-negative bacteria with a high profile of antimicrobial resistance were Klebsiella pneumoniae and Acinetobacter baumanii. The first one accounted for $57.1 \%$ of the cases, and they were only sensitive to ceftazidime/avibactam, while the second bacterium accounted for $96.4 \%$ of the isolates and they were only sensitive to colistin and tigecycline. VAP was the most common type of infection in both cases. In England, an outbreak due to Klebsiella pneumoniae has been reported in an ICU. Eleven of the 20 cases were reported to present with a hostile profile of antimicrobial resistance, which unfortunately has not been described, as well as the study's mortality rate ${ }^{29}$.

In Brazil, multidrug resistant Acinetobacter and enterobacteria are prevalent pathogens prior to the COVID-19 pandemic, and infections due to VAP have been the most frequent ICU-acquired infections ${ }^{30}$, as shown in a recent multi-hospital prevalence study of healthcare-associated infections in 28 adults patients that required ICU. In the European Union, resistance to carbapenems is also worrying and preceded the pandemic, and the impact of COVID-19 on antimicrobial resistance may become deleterious ${ }^{31}$.

In our ICU, the incidence of VAP at the onset of the pandemic was 10.6 cases per 1,000 ventilators-day and we saw that number peak to 18.9 cases per 1,000 ventilatorsday in June 2020. The incidence of autochthonous cases of carbapenem-resistant enterobacteriaceae was 0.5 cases per 1,000 patient-day in April 2020 and reached 6.4 cases per 1,000 patient-day in the following two months. The antimicrobial resistance profile of Klebsiella pneumoniae and Acinetobacter baumanii has become a major problem in our ICU. Our empirical scheme for nosocomial infections changed from the association of quinolone, aminoglycosides and oxazolidinones to the association of carbapenem, glycylcycline and polymyxin B.

In the months that followed the pandemic, many actions were implemented with the aim of reversing this scenario. The health teams were trained in hand hygiene and attire, we implemented a single-use coat policy for any patient colonized by multi-resistant bacteria, intensified training of ICU bed and room environment cleaning and disinfection, created a course on the rational use of antimicrobials for the hospital's clinical staff and created a multidisciplinary VAP prevention team to discuss opportunities for improvement.

The concern with infectious complications related to health care and coping with infections by antibiotic resistant bacteria is one of the most important public health issues of our time. The limited available evidence whether to initiate or not antibiotics for patients at the onset of the COVID-19 pandemic, the scarcity of evidence on antibiotic choice, the work overload of health professionals and the rapid deterioration of patients' clinical conditions have probably resulted in the indiscriminate use of antibiotics, contributing to the spread of multi-drug resistant microorganisms ${ }^{32,33}$. As limitations of our research, it is a single center observational study relying on the quality of medical records. Therefore, our findings cannot not be extrapolated to other ICUs.

\section{CONCLUSION}

In conclusion, we found a high incidence of healthcarerelated infections in patients with COVID-19 admitted to the ICU, with a higher prevalence of gram-negative bacteria and a high incidence of multidrug resistance. The most common infection was VAP. The SAPS 3 score was the only factor associated with infections acquired in the ICU. Secondary infections of any type and VAP were associated with a higher mortality. Despite the burden imposed by COVID-19, it is crucial that healthcare personnel maintain high standards of hand hygiene and specific precautions to contain hospital infections, and that antibiotics are prescribed judiciously in order to reduce resistance, otherwise, the ultimate goal of saving lives may not be achieved.

\section{CONFLICT OF INTERESTS}

The authors declare that they have no conflict of interests.

\section{FUNDING}

This research did not receive any specific grant from funding agencies in the public, commercial, or not-forprofit sectors.

\section{REFERENCES}

1. Johns Hopkins University \& Medicine. Coronavirus resource center. [cited $2021 \mathrm{Dec}$ 15]. Available from: https:// coronavirus.jhu.edu/ 
2. Jia L, Xie J, Zhao J, Cao D, Liang Y, Hou X, et al. Mechanisms of severe mortality-associated bacterial co-infections following influenza virus infection. Front Cell Infect Microbiol. 2017;7:338.

3. Morens DM, Taubenberger JK, Fauci AS. Predominant role of bacterial pneumonia as a cause of death in pandemic influenza: implications for pandemic influenza preparedness. J Infect Dis. 2008;198:962-70.

4. MacIntyre CR, Chughtai AA, Barnes M, Ridda I, Seale H, Toms R, et al. The role of pneumonia and secondary bacterial infection in fatal and serious outcomes of pandemic influenza a(H1N1) pdm09. BMC Infect Dis. 2018;18:637.

5. Grasselli G, Zangrillo A, Zanella A, Antonelli M, Cabrini L, Castelli A, et al. Baseline characteristics and outcomes of 1591 patients infected with SARS-CoV-2 admitted to ICUs of the Lombardy Region, Italy. JAMA. 2020;323:1574-81.

6. Arentz M, Yim E, Klaff L, Lokhandwala S, Riedo FX, Chong M, et al. Characteristics and outcomes of 21 critically ill patients with COVID-19 in Washington State. JAMA. 2020;323:1612-4.

7. Yang X, Yu Y, Xu J, Shu H, Xia J, Liu H, et al. Clinical course and outcomes of critically ill patients with SARS-CoV-2 pneumonia in Wuhan, China: a single-centered, retrospective, observational study. Lancet Respir Med. 2020;8:475-81.

8. World Health Organization. Clinical management of severe acute respiratory infection (SARI) when COVID-19 disease is suspected: interim guidance, 13 March 2020. [cited 2021 Dec 15] Available from: https://apps.who.int/iris/ handle/10665/331446

9. Alhazzani W, Møller MH, Arabi YM, Loeb M, Gong MN, Fan E, et al. Surviving sepsis campaign: guidelines on the management of critically ill adults with Coronavirus disease 2019 (COVID-19). Intensive Care Med. 2020;46:854-87.

10. Clinical and Laboratory Standards Institute. Performance standards for antimicrobial susceptibility testing: M100. $30^{\text {th }}$ ed. Wayne: CLSI; 2020.

11. Centers for Disease Control and Prevention. Types of healthcareassociated infections. [cited 2021 Dec 15]. Available from: https://www.cdc.gov/hai/infectiontypes.html

12. Durack DT, Lukes AS, Bright DJ. New criteria for diagnosis of infective endocarditis: utilization of specific echocardiografic findings. Am J Med. 1994;96:200-9.

13. Magiorakos AP, Srinivasan A, Carey RB, Carmeli Y, Falagas ME, Giske CG, et al. Multidrug-resistant, extensively drug-resistant, and pandrug-resistant bacteria: an international expert proposal for interim standard definitions for acquired resistance. Clin Microbiol Infect. 2012;18:268-81.

14. Ranieri VM, Rubenfeld GD, Thompson BT, Ferguson ND, Caldwell E, Fan E, et al. Acute respiratory distress syndrome: the Berlin Definition. JAMA. 2012;307:2526-33.

15. Langford BJ, So M, Raybardhan S, Leung V, Westwood D, MacFadden DR, et al. Bacterial co-infection and secondary infection in patients with COVID-19: a living rapid review and meta-analysis. Clin Microbiol Infect. 2020;26:1622-9.

16. Ruiz J. Enhanced antibiotic resistance as a collateral COVID-19 pandemic effect? J Hosp Infect. 2021;107:114-5.

17. Ripa M, Galli L, Poli A, Oltolini C, Spagnuolo V, Mastrangelo A, et al. Secondary infections in patients hospitalized with COVID-19: incidence and predictive factors. Clin Microbiol Infect. 2020:27:451-7.

18. Perez S, Innes GK, Walters MS, Mehr J, Arias J, Greeley R, et al. Increase in hospital-acquired Carbapenem-resistant Acinetobacter baumannii infection and colonization in an acute care hospital during a surge in COVID-19 admissions: New Jersey, February-July 2020. MMWR Morb Mortal Wkly Rep. 2020;69:1827-31.

19. Duployez C, Le Guern R, Milliere L, Caplan M, Loïez C, Ledoux G, et al. One outbreak can hide another. Jpn J Infect Dis. 2021;74:367-8.

20. Sharifipour E, Shams S, Esmkhani M, Khodadadi J, FotouhiArdakani R, Koohpaei A, et al. Evaluation of bacterial co-infections of the respiratory tract in COVID-19 patients admitted to ICU. BMC Infect Dis. 2020;20:646.

21. Nebreda-Mayoral T, Miguel-Gómez MA, March-Rosselló GA, Puente-Fuertes L, Cantón-Benito E, Martínez-García $\mathrm{AM}$, et al. Bacterial/fungal infection in hospitalized patients with COVID-19 in a tertiary hospital in the Community of Castilla y León, Spain. Enferm Infecc Microbiol Clin. 2020 In Press.

22. Garcia-Vidal C, Sanjuan G, Moreno-García E, Puerta-Alcalde P, Garcia-Pouton N, Chumbita M, et al. Incidence of co-infections and superinfections in hospitalized patients with COVID-19: a retrospective cohort study. Clin Microbiol Infect. 2021;27:838.

23. Fu Y, Yang Q, Xu M, Kong H, Chen H, Fu Y, et al. Secondary bacterial infections in critical ill patients with Coronavirus disease 2019. Open Forum Infect Dis. 2020;7:ofaa220.

24. Zhang H, Zhang Y, Wu J, Li Y, Zhou X, Li X, et al. Risks and features of secondary infections in severe and critical ill COVID-19 patients. Emerg Microbes Infect. 2020;9:1958-64.

25. Dudoignon E, Caméléna F, Deniau B, Habay A, Coutrot M, Ressaire Q, et al. Bacterial pneumonia in COVID-19 critically ill patients: a case series. Clin Infect Dis. 2021;72:905-6.

26. Baiou A, Elbuzidi AA, Bakdach D, Zaqout A, Alarbi KM, Bintaher AA, et al. Clinical characteristics and risk factors for the isolation of multi-drug-resistant Gram-negative bacteria from critically ill patients with COVID-19. J Hosp Infect. 2021;110:165-71.

27. Giacobbe DR, Battaglini D, Ball L, Brunetti I, Bruzzone B, Codda $\mathrm{G}$, et al. Bloodstream infections in critically ill patients with COVID-19. Eur J Clin Invest. 2020;50:e13319.

28. Weiner-Lastinger L, Pattabiraman V, Konnor R, Patel P, Wong E, Xu S, et al. The impact of coronavirus disease 2019 
(COVID-19) on healthcare-associated infections in 2020: A summary of data reported to the National Healthcare Safety Network. Infect Control Hosp Epidemiol. 2021:1-14.

29. Sturdy A, Basarab M, Cotter M, Hager K, Shakespeare D, Shah $\mathrm{N}$, et al. Severe COVID-19 and healthcare-associated infections on the ICU: time to remember the basics? J Hosp Infect. 2020;105:593-5.

30. Braga IA, Campos PA, Gontijo-Filho PP, Ribas RM. Multihospital point prevalence study of healthcare-associated infections in 28 adult intensive care units in Brazil. J Hosp Infect. 2018;99:318-24.
31. Monnet DL, Harbarth S. Will coronavirus disease (COVID-19) have an impact on antimicrobial resistance? Euro Surveill. 2020;25:2001886.

32. Rawson TM, Moore LS, Castro-Sanchez E, Charani E, Davies F, Satta G, et al. COVID-19 and the potential long-term impact on antimicrobial resistance. J Antimicrob Chemother. 2020;75:1681-4.

33. Zhou P, Liu Z, Chen Y, Xiao Y, Huang X, Fan XG. Bacterial and fungal infections in COVID-19 patients: a matter of concern. Infect Control Hosp Epidemiol. 2020;41:1124-5. 